\title{
Rothmund-Thomson syndrome: two case reports show heterogeneous cutaneous abnormalities, an association with genetically programmed ageing changes, and increased chromosomal radiosensitivity
}

\author{
B Kerr, G S Ashcroft, D Scott, M A Horan, M W J Ferguson, D Donnai
}

Department of

Medical Genetics, St

Mary's Hospital,

Hathersage Road, Manchester M13 0JH, UK

B Kerr

D Donnai

Department of Geriatric Medicine, University Hospital of South Manchester, Manchester, UK G S Ashcroft M A Horan

Cells, Immunology and Development, 3.239 School of Biological Sciences, Stopford Building, Oxford Road, University of Manchester, Manchester, UK G S Ashcroft $M$ W J Ferguson

Christie CRC Research Centre, Withington, Manchester, UK D Scott

Correspondence to: Dr Kerr.

Received 18 December 1995 Revised version accepted for publication 1 July 1996

\begin{abstract}
Rothmund-Thomson syndrome is a rare, autosomal recessive disorder associated with characteristic cutaneous changes, sparse hair, juvenile cataracts, short stature, skeletal defects, dystrophic teeth and nails, and hypogonadism. Mental retardation is unusual. An increased incidence of certain malignancies has been reported. Clonal or mosaic chromosome abnormalities and abnormalities in DNA repair mechanisms have been reported in some cases. We report two cases of RothmundThomson syndrome, both with intellectual handicap, associated in one with a previously undescribed histological appearance of involved skin, suggesting that the spectrum of abnormalities is even more heterogeneous than previously presumed. Both cases exhibited chromosomal radiosensitivity of lymphocytes which may be an indication of a DNA repair defect. This is the first report of an association between Rothmund-Thomson syndrome and unique, intrinsic, age related skin changes.
\end{abstract}

(f Med Genet 1996;33:928-934)

Key words: Rothmund-Thomson; skin; photoageing; DNA repair.

The principal characteristics of what is now called the Rothmund-Thomson syndrome were established from the descriptions of the original families by August Rothmund and, 67 years later, by Seefelder. ${ }^{1}$ Rothmund, in 1868 , after seeing a 5 year old boy in his clinic in Munich with a peculiar marmorisation of the skin and unilateral cataract, visited the isolated area of the Bavarian Alps in which the family lived. He found an affected family in several towns, all containing a number of children with poikiloderma with and without cataract. Rothmund stated that the skin abnormalities were the most important and consistent changes but that the body habitus of all the affected people was the same. Seefelder reported that one of the affected persons was very short in stature with small hands and short fingers and very short forearms and lower legs. Some of the affected females in these original families had sparse hair ${ }^{1}$ and only one had had children. ${ }^{2}$

The principal clinical characteristics of the syndrome were thus established as universal skin changes, namely striae, atrophy, and ab- normal pigmentation, ${ }^{1}$ short stature, variable cataract, hypogonadism, and sparse hair. Bloch and Stauffer ${ }^{3}$ in 1929 reported two cases with marked hypogonadism, dystrophic nails, and developmental abnormalities of the teeth.

Thomson ${ }^{4}$ in 1923 published a report of two sisters with a previously undescribed disorder. In $1936,{ }^{5}$ he reviewed these cases and reported a third case. He named the disorder "poikiloderma congenitale", with poikiloderma meaning "variable skin". His patients are the first reports of limb reduction defects, eye abnormalities other than cataract, and a distinctive facial appearance. ${ }^{45}$

Taylor $^{1}$ in 1957 summarised most of the published cases of congenital poikiloderma with and without cataracts and suggested that the syndromes described by Rothmund and Thomson were the same. Since that time, patients with a similar constellation of findings are referred to as having Rothmund-Thomson syndrome, although it has been subsequently suggested that the disorders described by Rothmund and Thomson may not be the same. ${ }^{6}$

A number of reviews of Rothmund-Thomson syndrome have been published. ${ }^{17-9}$ From these, the estimated frequencies of the commonest characteristics are not always consistent (table 1). Mental retardation has been reported in $13 \%$ of patients ${ }^{8}$ but in only six patients in a review of 202 cases. $^{9}$

Segregation analysis is consistent with autosomal recessive inheritance. ${ }^{7}$ Consanguinity has been reported in $16 \%{ }^{7}$ to $27 \%{ }^{9}$ and the condition as "familial" in 59 to $70 \% .^{19} \mathrm{~A}$ female excess has been reported by a number of authors, ${ }^{17}$ but not by others. ${ }^{910}$ Occurrence in a mother and child suggests the possibility of genetic heterogeneity or else pseudodominance. ${ }^{710}$

Clonal or mosaic chromosome abnormalities and abnormalities in DNA repair mechanisms have been reported in some cases. ${ }^{911-15}$

Table 1 Reported frequencies of commonest characteristics in Rothmund-Thomson syndrome

\begin{tabular}{ll}
\hline & $\%$ \\
\hline Poikiloderma & $100^{78}$ \\
Poikiloderma, onset in infancy & $89^{9}-93^{8}$ \\
Thin hair, sparse/absent eyebrows and lashes & $60-65^{89}$ \\
Cataracts & $45-47^{89}$ \\
Short stature & $62^{8}-100^{7}$ \\
Musculoskeletal, bone defects, or small hands & $78^{8}-95^{7}$ \\
Hypogonadism & $29^{8}-94^{7}$ \\
Abnormal teeth & $27^{8}-59^{7}$ \\
Dysplastic nails & $22^{8}-42^{7}$ \\
\hline
\end{tabular}




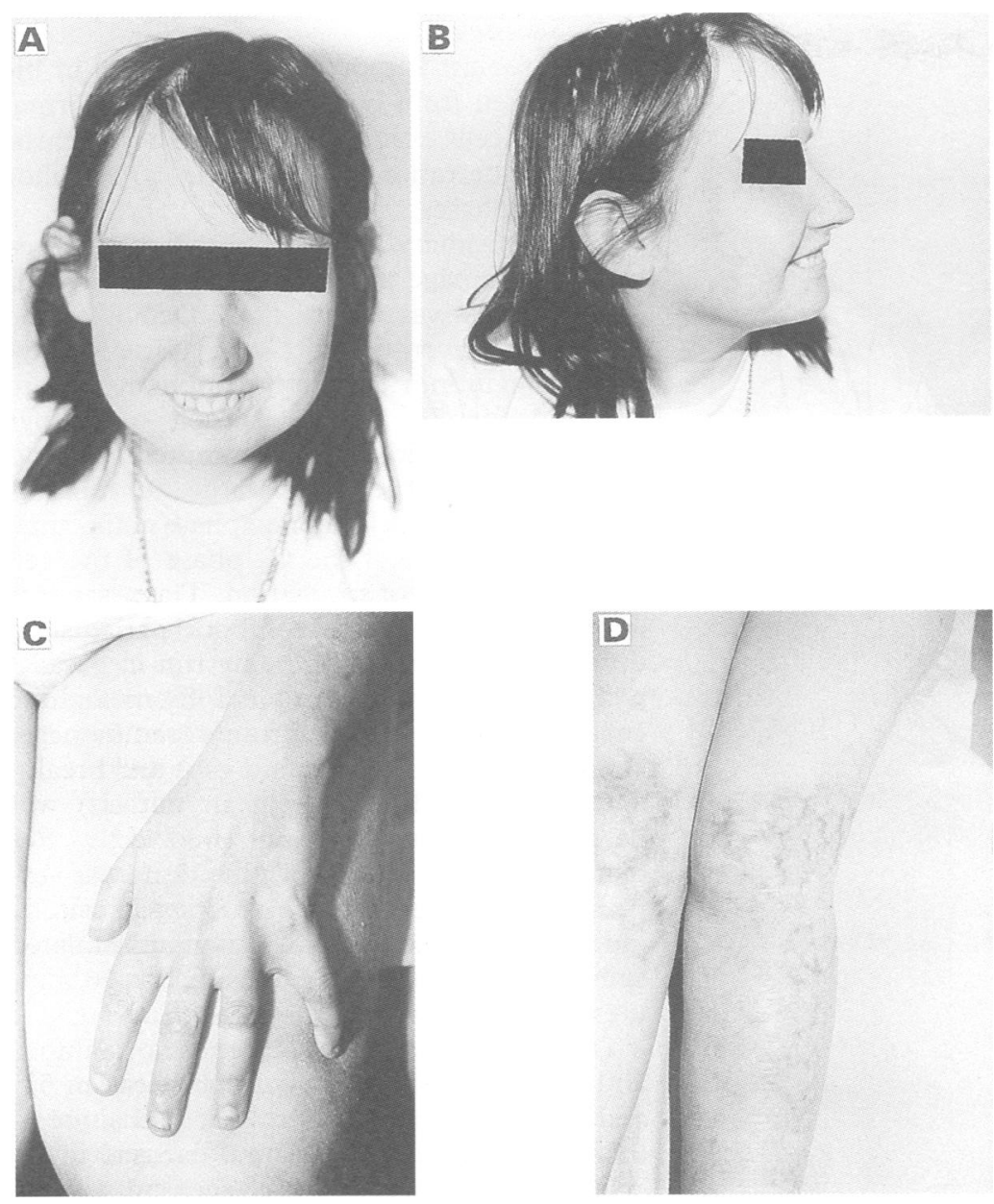

Figure 1 ( $A, B)$ Case 1 aged 27. (C) Short fingers and thumb. (D) Macroscopic skin changes: extensor lower limb. (All photographs reproduced with permission.)

We report two isolated cases of RothmundThomson syndrome, both with mental retardation, in whom the diagnosis was delayed owing to prominent non-dermatological manifestations.

\section{Case reports}

CASE 1

This was the second child of young, non-consanguineous parents of Anglo-Saxon origin. The maternal age was 28 years at delivery. The pregnancy was complicated by bleeding at 18 weeks' gestation and premature rupture of the membranes at 31 weeks' gestation. She was delivered vaginally with a breech presentation. The birth weight was $1590 \mathrm{~g}$, length $44 \mathrm{~cm}$, and head circumference $29 \mathrm{~cm}$, all 50 th to 75 th centile. There were no neonatal problems and no concerns about her growth or development at 4 months of age. There is one male sib who is well.

She was re-referred for developmental assessment aged 3 years. Growth parameters were all on the 3rd centile and developmental assessment gave an intelligence quotient of 67 . She had a history of diarrhoea and was investigated for malabsorption but no cause was found.

When seen in the genetic department aged 11 , a history was given of recurrent respiratory tract infections and diarrhoea in the first years of life. She had walked at 3 years. Her first teeth were reported as black and stubby. There was a history of huge fluid filled blisters on slight exposure to the sun. The abnormal features noted on examination were short stature, a dorsal kyphosis, thin facial skin with broken veins and many freckles, dysplastic finger nails, mild ataxia, and marked dysdiadokinesis.

Her growth failure was investigated at the age of 13. A photosensitive dermatitis, short thumbs, and thin sparse hair were noted. Menarche had occurred at the age of 12 and her menstruation was and remains regular. Bilateral embryonic nuclear cataracts were seen with visual acuity of $6 / 24$ in both eyes.

Normal investigations included routine biochemistry and haematology, growth hormone, adrenal function, thyroid function, and gonadotrophins. On $x$ ray, facial bone size was small in comparison with the size of the skull vault, there was mild right sided coxa vara, and dense lumbar vertebral bodies with abnormal texture and translucencies. Bone age had been consistent with chronological age on several occasions.

She was reinvestigated at the age of 19 because of obesity. Routine biochemistry, haematology, thyroid function, 24 hour urine cortisol, and dexamethasone suppression test were all normal.

She presented for review in the genetic department at the age of 27 (fig 1). She was short and microcephalic: weight $49.6 \mathrm{~kg}$ (25th centile), height $139 \mathrm{~cm}(-4 \mathrm{SD})$, and head circumference $51 \mathrm{~cm}$ (<3rd centile). The fingers were all short (midfinger length less than the 3 rd centile) but the thumbs most obviously so. She had a dorsal kyphosis and immature facies with a high pitched voice. The forehead was centrally prominent, the palpebral fissures were upward slanting, and the eyes deeply set and small (palpebral fissure length $2.5 \mathrm{~cm}$, less than the 3rd centile). The nose was long and pointed and the philtrum short. The palate was high arched and the ears protuberant. There was truncal obesity. Pubertal development was normal. The scalp hair was sparse and the nails dysplastic but the teeth were normal.

On radiography, there was a short first metacarpal, increased density of the lumbar spine with premature degenerative changes, and increased density of the skull vault and base with pronounced hyperostosis frontalis.

\section{Macroscopic skin changes}

The skin on the face was atrophic with telangiectasia, broken veins, and scarring. Marked atrophic, depigmented changes and small telangiectatic lesions were apparent over the extensor areas of both lower limbs (fig 1). Skin appearance was normal elsewhere.

\section{Microscopic cutaneous changes (fig 2)}

A $3 \mathrm{~mm}$ punch biopsy specimen was obtained from the atrophic, depigmented area on the right shin and from skin which appeared macroscopically normal from the right upper inner arm (a non-sun exposed site). Tissue sections were fixed in $10 \%$ formal saline, embedded in paraffin wax, and cut at $7 \mu \mathrm{m}$ thickness on a Leitz microtome. Haematoxylin and eosin $(\mathrm{H} \& \mathrm{E})$ and aldehyde fuschin stained slides 


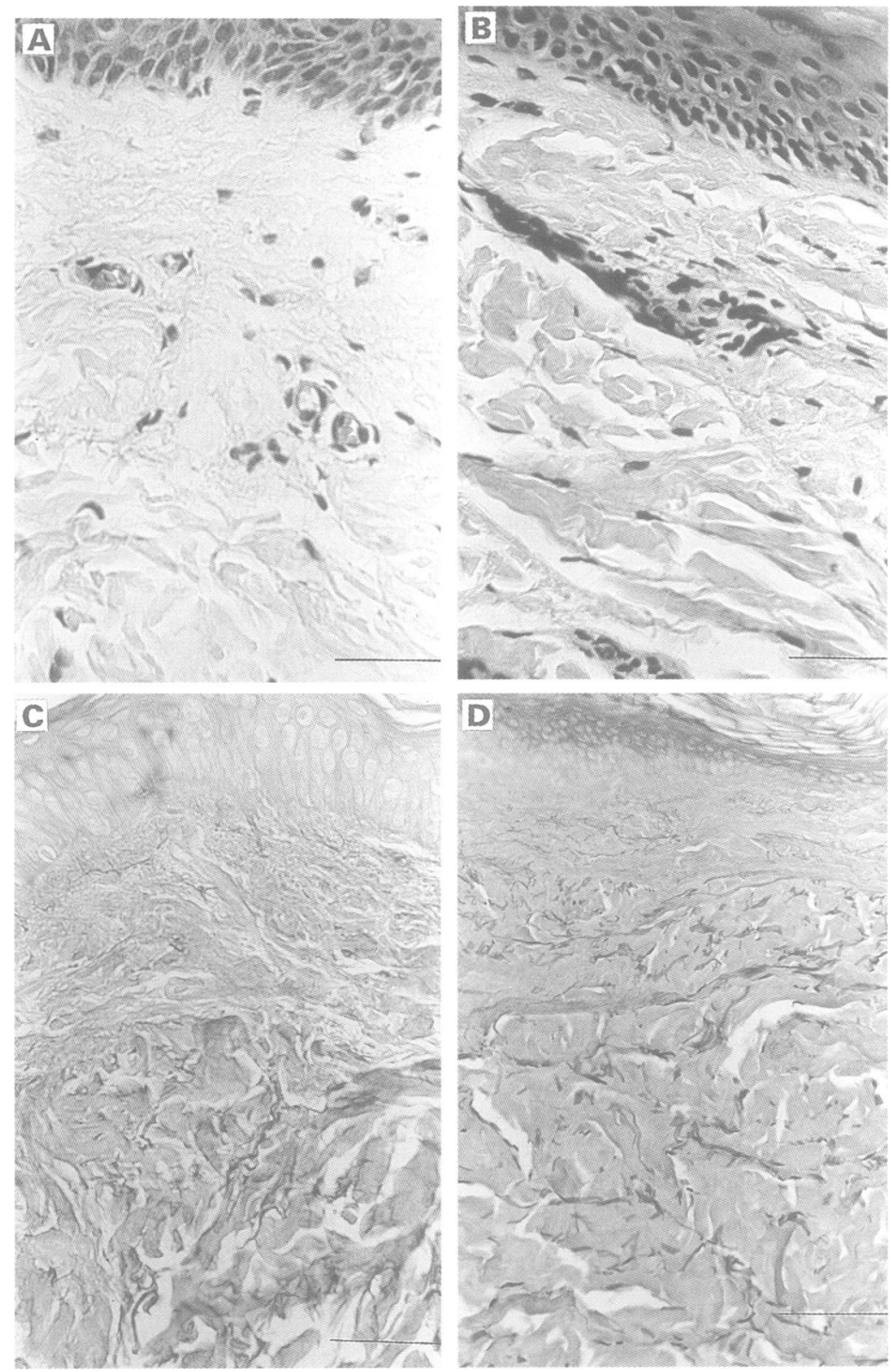

Figure 2 Microscopic cutaneous changes. Scale bar $=100 \mu \mathrm{m}$. (A) HE्E from unaffected area, upper inner arm. (B) $H \mathcal{E} E$ from affected area, right shin. $(C)$ Aldehyde fuschin from unaffected area, upper inner arm. (D) Aldehyde fuschin from affected area, right shin.

\section{Other investigations}

Skin fibroblast karyotypes were normal in biopsies taken from both normal and abnormal skin in 30 cells examined. No strucutural chromosome aberrations were seen in 50 lymphocyte metaphases.

The sensitivity of lymphocytes to chromosome damage and mitotic inhibition after $\mathrm{X}$ irradiation was investigated. Details of the method are given in Scott et al. ${ }^{16}$ Briefly, phytohaemogglutinin stimulated lymphocytes were cultured for 72 hours, exposed to $x$ rays $(0.5 \mathrm{~Gy})$, colcemid added 30 minutes later, and cells harvested at ice temperature 90 minutes after irradiation. Cells in metaphase at this time would have been in the $G_{2}$ phase of the cell cycle at the time of irradiation. The assay was applied to lymphocytes of both patients on different occasions, each being run in parallel with a healthy control sample. Fifty metaphase cells were analysed for chromosome damage, comprising mainly chromatid gaps and breaks. The mitotic index (\% cells in mitosis) was determined from counting 1000 cells. Radiation induced mitotic inhibition was expressed as the percentage reduction in mitotic index of irradiated compared with unirradiated cells. Mitotic inhibition is maximal at $90 \mathrm{~min}$ utes after irradiation. ${ }^{17}$

Our previous studies ${ }^{18}$ and those of Sanford and Parshad ${ }^{1920}$ have shown that between 5\% and $10 \%$ of healthy controls are sensitive to the induction of chromosome damage in $G_{2}$ cells and that sensitivity is seen in a wide range of cancer predisposing conditions (see Discussion). The vertical dashed line, at 105 aberrations per 100 cells in fig 3, indicates the discrimination between a normal and a sensitive response; $7 / 74$ controls were sensitive (top panel). The patient was within the sensitive range ( 134 aberrations $/ 100$ cells, middle panel) whereas the parallel control was not $(94 / 100$ cells, bottom panel). There was no difference in mitotic inhibition between the patient $(89 \%)$ and parallel control $(87 \%)$.

CASE 2

She was born at term with a birth weight of $2500 \mathrm{~g}$ in comparison with her sibs' weights of 3900 and $4150 \mathrm{~g}$. Her non-consanguineous parents were aged 24 and 25 at the time of her birth and are of British ancestry. There were no perinatal problems although she fed poorly and had poor weight gain. She has had multiple urinary tract infections, the first at 3 months. Repair of vesicoureteric reflux was undertaken at the age of 4 years. She subsequently developed bladder stones. She has had no further urinary tract infections since their removal and her growth improved. She has had a fractured humerus with no history of trauma and three further limb fractures following minimal trauma. Recently she developed ataxia and transient right hemiparesis in association with a viral encephalitis.

All her milestones were delayed; she walked at 21 months and had only two words by the age of 3 . She is now in special school. Clinically she functions in the moderately intellectually orientated in a parallel fashion in the reticular dermis of the atrophic skin with a loss of the arcade network. 


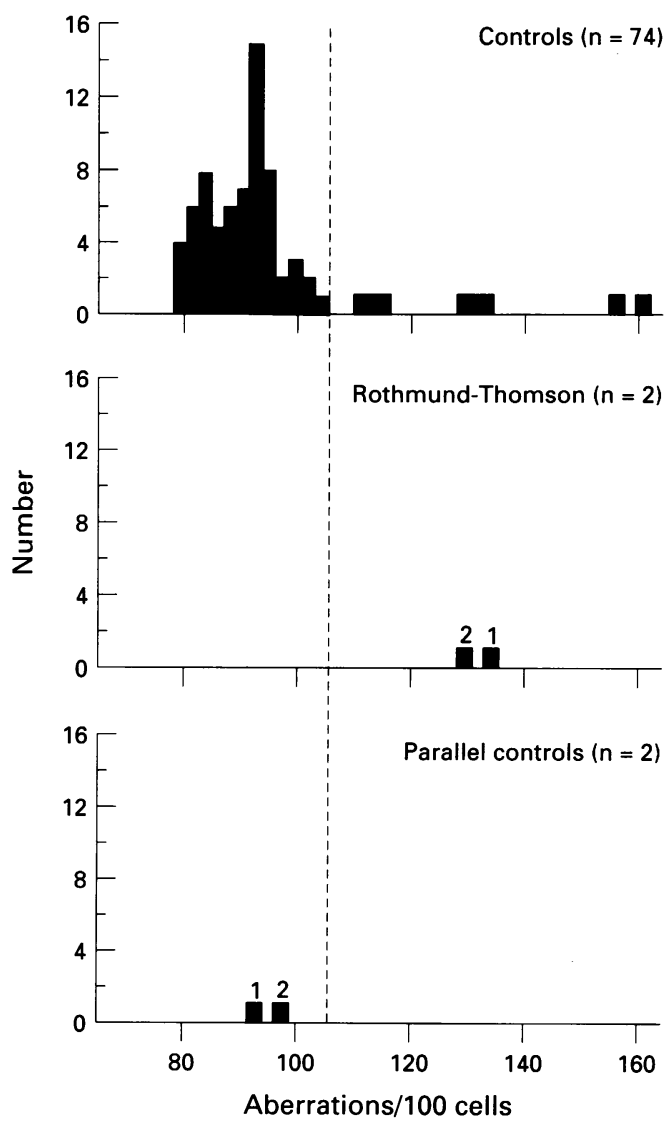

Figure $3 X$ ray induced chromosome damage in $G 2$ lymphocytes. Top panel: radiosensitivity of 74 healthy controls (from ref 17). Middle panel: sensitivity of the two Rothmund-Thomson cases. Bottom panel: sensitivity of healthy controls tested in parallel with the two cases. The vertical dashed line discriminates between a normal and sensitive response. ${ }^{17}$

handicapped range. Her parents remember her as always being small. She was started on growth hormone at $7 \frac{1}{2}$ years and has had a good growth response despite no demonstrable growth hormone deficiency. Formal eye assessment was normal.

In retrospect, the first skin change noted was a white patch on her forehead which would
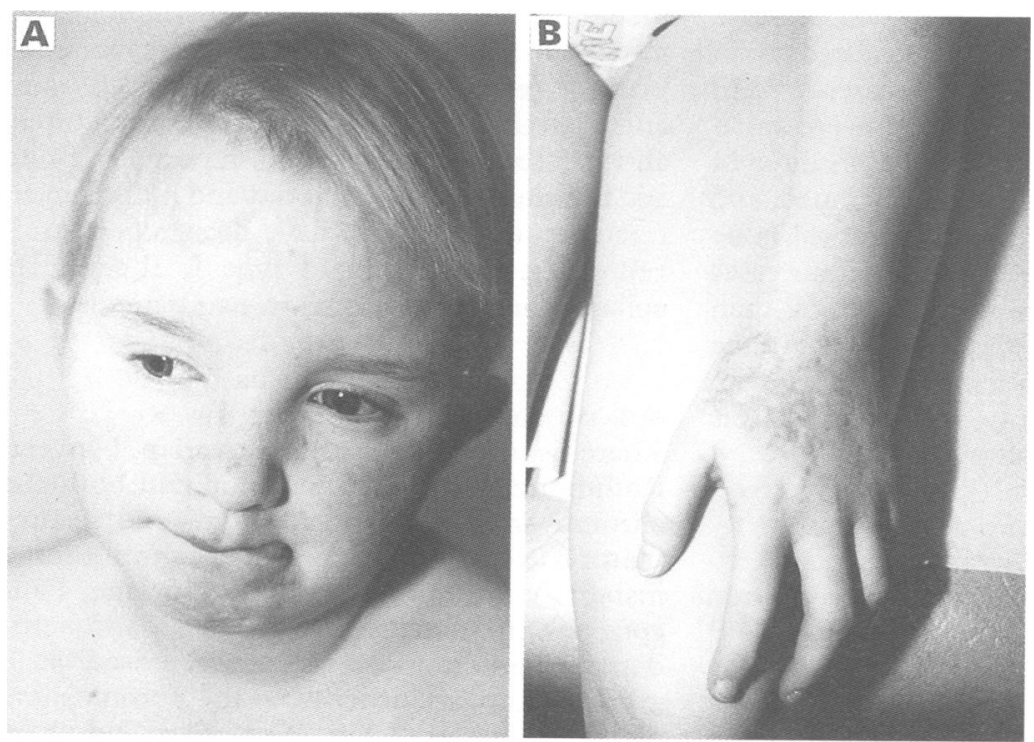

Figure 4

(A) Case 2 aged 9. (B) Macroscopic skin changes of the hand. remain white when she cried. Dry facial skin was also noted and erythema down the side of her face. A red rash was noticed on her hands at the age of 7 . She has very sparse hair and is very blonde for her family. She is very sun sensitive but has never blistered.

On examination at 9 years 11 months (fig 4), she was short with a height of $119 \mathrm{~cm}$ (approximately $3 \mathrm{SD}$ less than the mean), weight $22.9 \mathrm{~kg}$ ( $3 \mathrm{rd}$ centile), and a head circumference of $49 \mathrm{~cm}$ (below the $3 \mathrm{rd}$ centile). She had deep set eyes and a high rounded forehead with a receding hairline. She had a thin nose and short philtrum with mild micrognathia, teeth crowding, and simple protuberant ears. She was hyperextensible at the elbows and had small hands and short big toes. Her teeth and eyes were normal. On $x$ ray of hand, foot, and forearm, the first metatarsal was short.

\section{Macroscopic skin changes (fig 4)}

She had reticular and linear erythema with atrophy on her face and extensor surfaces of the hands. A $4 \times 3 \mathrm{~cm}$ atrophic, depigmented, inverted lesion was present on the forehead, with erythematous patches on both cheeks.

\section{Microscopic skin changes (fig 5)}

A $2 \mathrm{~mm}$ punch biopsy specimen was removed from a poikilodermatous region from the dorsum of the right hand. Tissue processing was as previously described. $\mathrm{H} \& \mathrm{E}$ staining showed hyperkeratosis with thick bundles of collagen arranged in a parallel fashion throughout the dermis. Numerous dilated, tortuous blood vessels in the papillary dermis were associated with a mild perivascular inflammatory infiltrate. Elastin fibres highlighted by aldehyde fuschin stain appeared fragmented with a loss of the dermoepidermal network and an increase in mid-dermal fibres.

\section{Other investigations}

Karyotypes from lymphocyte cultures were normal on several occasions. The skin biopsy for fibroblast karyotype failed to grow. Only one chromosome break was seen in 50 lymphocyte metaphases, which was well within our normal range. ${ }^{17}$ Sensitivity in the $G_{2}$ chromosomal radiosensitivity assay (130 aberrations/100 cells) was similar to that of case 1 and greater than the parallel control (98/100 cells, fig 3). Mitotic inhibition was similar in the case $(94 \%)$ and parallel control (93\%).

\section{Discussion}

We present two cases with clinical features of Rothmund-Thomson syndrome in both of whom the diagnosis was delayed and the clinical picture dominated by developmental delay and poor growth. Both have poikilodermatous skin changes affecting predominantly extensor skin surfaces, sparse hair, short stature, microcephaly, and small hands and feet with a short first metatarsal in one and short first metacarpal 


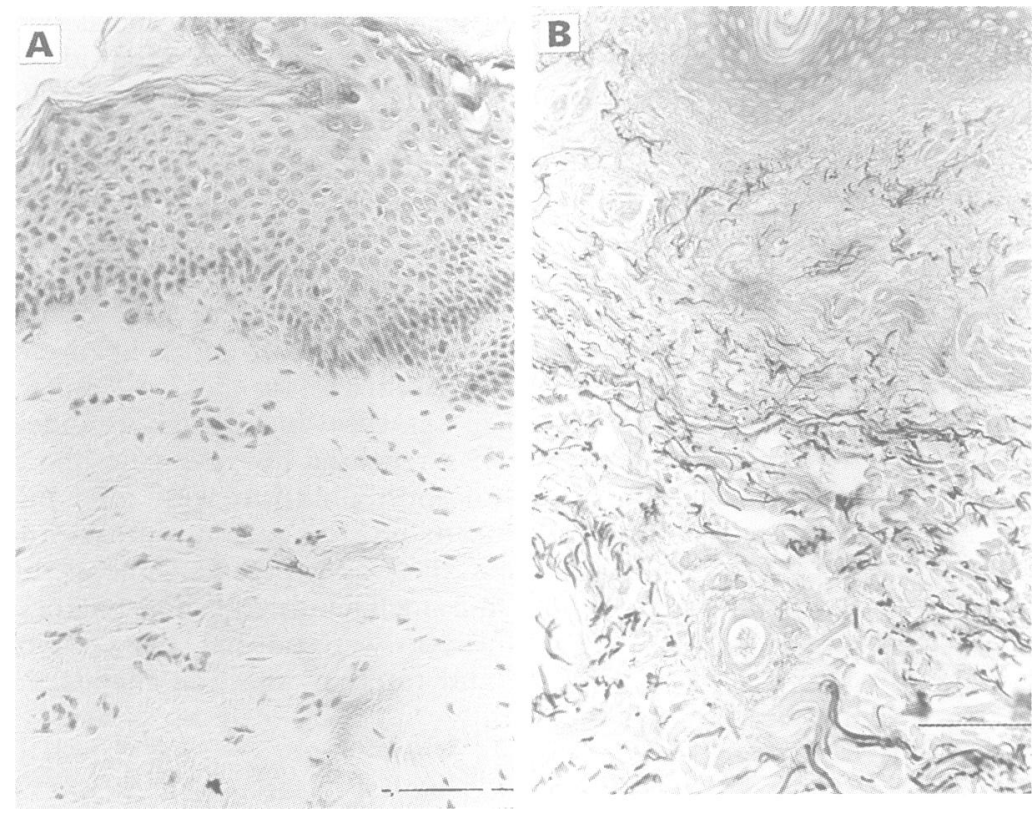

Figure 5 Microscopic cutaneous changes. Scale bar $=100 \mu m$. (A) HEE from affected area, right hand. (B) Aldehyde fuschin from affected area, right hand.

in the other. In case 1 , bilateral embryonic nuclear cataracts are present and the nails are dysplastic. Both are isolated cases and there is no history of parental consanguinity.

A number of authors have reported that the non-dermatological manifestations of Rothmund-Thomson syndrome can dominate the clinical picture, particularly intrauterine growth retardation affecting both height and weight, severe short stature, ${ }^{21}$ failure to thrive, ${ }^{1121-23}$ and skeletal deformity. ${ }^{24}$

\section{MENTAL RETARDATION}

Mental retardation is an uncommon feature of Rothmund-Thomson syndrome. It has been suggested that patients with severe growth retardation, major skeletal abnormalities, and ectodermal dysplasia and no cataract represent a subgroup, some of whom have mental retardation. ${ }^{25}$

A review of the previously reported cases with mental retardation ${ }^{11212326}$ does not indicate specific associated phenotypic features. Skin biopsy was not reported in two cases. ${ }^{21}{ }^{23}$ All the children were short but not all were small at birth, bone $x$ rays were abnormal in three of the five cases in whom they were performed, and in one of these $e^{21}$ there was asymmetrical bone shortening. Cataracts were present in four cases but the remaining two cases were both less than 2 years old at the time of the report. Five of the cases were said to have a flat nasal bridge with or without frontal bossing. Microcephaly was present in most but not all cases. ${ }^{11}$

\section{FACIAL FEATURES}

A distinctive facial appearance in this condition was first described in the report of Thomson ${ }^{5}$ and a number of different facial features have since been described in patients of different ages. Our cases have certain facial features in common which are not those reported in the other patients with developmental problems. They most resemble case 1 of Hall et al, ${ }^{21}$ a patient with normal intelligence, flat supraorbital ridges, a flat high forehead, a long, thin, and prominent nose, and mild micrognathia. Skin biopsy was not reported in this case. Part of the variability in facial features may reflect variable ages of reporting. A long and prominent nose with a short philtrum is illustrated in case 1 of Thomson ${ }^{5}$ whereas in the earlier photograph of the same case and her affected sib, ${ }^{4}$ a "saddle nose" is a more appropriate description.

\section{EYE ABNORMALITIES}

That cataracts are not always present was established in the reports of the original families and the cases of Thomson. ${ }^{1459}$ When present, cataracts usually develop before the age of 6 years, but may not occur until the third decade. ${ }^{24}$ They are bilateral, of rapid onset, and subcapsular in type, unlike the embryonic nuclear cataracts in our case 1 . A variety of other eye abnormalities have been reported, including congenital glaucoma, corneal atrophy, iris colobomata, ${ }^{27}$ retinal colobomata and atrophy, ${ }^{9}$ microphthalmia and photophobia, ${ }^{27}$ and Rieger anomaly. ${ }^{24}$

\section{SKELETAL ABNORMALITIES}

Small hands and feet have been reported frequently. ${ }^{27}$ Absent metacarpals and phalanges of the thumbs bilaterally with reduction deformities of the ulnae and radii or total absence of the radii have been reported in a number of patients. ${ }^{5122}$ Hyperextensibility of the small joints of the hand, ${ }^{24}{ }^{28}$ contractures of the large joints, ${ }^{24}$ bilateral subluxation of the knees, ${ }^{21}$ and kyphoscoliosis have been reported. ${ }^{21} 24$

A number of different $x$ ray anomalies have been described including osteoporosis, patchy sclerosis, and cystic changes of long bones, ${ }^{12124}$ shallow olecranon fossae with dislocation of the radial heads, upward subluxation of humeral heads, flattened capital femoral epiphyses with short femoral necks, undertubulation of the metaphyses, and elongation of the lumbar vertebral bodies with irregular concave endplates. ${ }^{24}$ Asymmetry of limb size, ${ }^{121}$ cleft hand and cleft foot, ${ }^{1}$ achilles tendon contractures, and talipes have also been reported. ${ }^{9}$ Bone age may be markedly delayed and pathological fractures, as in case 2 , have been reported. ${ }^{924}$ Fibroblast production of type I, II, and III collagen has been normal in two patients. ${ }^{24}$

\section{CHROMOSOME ABNORMALITIES}

There is some phenotypic overlap between Rothmund-Thomson syndrome and both the chromosome instability syndromes and the premature ageing syndromes. The chromosome instability syndromes, Bloom syndrome, Fanconi anaemia, ataxia telangiectasia, and xeroderma pigmentosum are characterised as a group by hypersensitivity to the chromosome damaging effects of certain chemical and physical agents and a predisposition to neoplasia. 
Clinically, these disorders produce varying combinations of skin, immune or haematological, and neurological symptoms with an increased risk for malignancy. ${ }^{29}$

In Rothmund-Thomson syndrome, clonal chromosome abnormalities in involved skin have been reported twice ${ }^{1112}$ and interpreted as representing in vitro chromosome instability. ${ }^{11}$ In one of these patients, there was stable trisomy 8 mosaicism in blood lymphocytes. ${ }^{12}$ In a third patient, instability of both lymphocyte and fibroblast chromosomes from an area of involved skin have been found. ${ }^{13}$

No evidence of clonal chromosome abnormalities has been found in our patients although the reported mosaicism is often of very low frequency and only 30 cells from skin fibroblast cultures were examined in our patients. In addition, in case 2 , the cells from involved skin did not grow.

Neither case showed a raised level of spontaneous chromosome breakage but both exhibited chromosomal radiosensitivity to $x$ rays, which is seen in many cancer predisposing conditions, such as ataxia telangectasia (AT, homozygotes, ${ }^{3031}$ heterozygotes ${ }^{1831}$ ), Bloom syndrome, ${ }^{2032}$ Fanconi anaemia, ${ }^{2033}$ xeroderma pigmentosum $^{34}$ (homozygotes and heterozygotes), hereditary retinoblastoma ${ }^{35} \mathrm{Li}-\mathrm{Frau}-$ meni syndrome, ${ }^{36}$ and others. ${ }^{19}$ The levels of damage in cases 1 and 2 (134 and 130 aberrations per 100 cells, respectively) were considerably lower than our mean value of 341 (range 232-715) for AT homozygotes, but overlapped those for AT heterozygotes (mean = 145 , range 106-176). ${ }^{18}$

Parshad et $a l^{20}$ have provided evidence that, in at least some cancer prone groups, chromosomal radiosensitivity is a consequence of defects in DNA repair. An alternative explanation, that sensitivity may arise from defects in cell cycle checkpoint control, allowing insufficient time for repair, ${ }^{1737}$ does not appear to be the case for these two patients because both exhibited mitotic inhibition levels well within the normal range ${ }^{17}$ and similar to their parallel controls.

Sensitivity to the lethal effects of ionising radiation and decreased DNA repair capacity has been reported in two of four fibroblast strains from Rothmund-Thomson cases. ${ }^{15}$ Most studies of cellular response to ultraviolet radiation have detected no abnormality, ${ }^{9}$ although there have been two reports of radiation sensitivity and reduced repair. ${ }^{148}$

\section{SKIN CHANGES}

The macroscopic skin changes of RothmundThomson syndrome are a universal finding and consist of reticulated, linear, or punctate atrophy, telangiectasia, and depigmentation or hyperpigmentation which may be smudged or reticulated. The initial phase is erythematous, and involves predominately sun exposed skin with initial involvement of the cheeks, forehead, ears, and neck with spread to extensor aspects of the hands, legs, and buttocks. ${ }^{9}$ Sun sensitivity, which improves with age, may occur with bullae formation on even slight exposure, ${ }^{1}$ both features present historically in case 1 .
The erythematous phase is followed after several years by the chronic poikilodermatous stage affecting predominantly extensor surfaces. However, the erythematous phase does not always occur, ${ }^{21}$ and while the onset of cutaneous change is within the first year of life in $89 \%$, skin changes can be present at birth ${ }^{19}$ and may not appear until 2 to 3 years of age. ${ }^{29}$ Calcinosis, hyperkeratosis, and actinic keratoses have been reported only rarely; however spontaneous remission has not. In case 2 , in retrospect, an area of atrophy and mild erythema of facial skin was present in the first year of life but the changes were not obvious and the diagnosis was not apparent before the development of striking chronic skin changes.

Other inherited syndromes associated with poikiloderma, photosensitivity, and abnormal DNA repair include Cockayne syndrome, in which cachexia and moderate to severe mental retardation are characteristic, and progeria which has sclerodermatous-like changes and a median lifespan of 13 years with death resulting from cardiovascular disease. The latter has been termed a "premature ageing syndrome" because of observed similarities with the normal ageing process, including a reduced fibroblast life span in vitro. However, the skin changes are similar to photoageing with fibrotic, thickened collagen, and not intrinsic ageing as reported in case 1 . Other premature ageing syndromes not associated with poikiloderma but with manifestations of cutaneous ageing, such as Werner syndrome, pseudoxanthoma elasticum, and elastoderma, are all associated with thickened collagen fibres and the accumulation of elastotic material as seen in photoaged skin. ${ }^{39}$ Two syndromes (cutis laxa and the wrinkly skin syndrome) have been reported to show only one manifestation of intrinsic cutaneous ageing, generalised fragmented dermal elastin fibres. ${ }^{39}$

The macroscopic abnormalities of atrophy and dyspigmentation are similar to those seen in photoageing. Photoageing is a pathological process owing to a combination of intrinsic skin ageing coupled with accumulated UV damage. ${ }^{40}$ Ageing itself is defined as a loss of cellular homeostasis secondary to a failure to maintain cellular repair mechanisms, such as DNA repair. There are obvious parallels between the microscopic changes found in photoaged skin and those seen in case 2, such as hyperkeratosis, densely packed papillary collagen, inflammatory infiltrate, and mid-dermal elastosis. Thus, the cutaneous manifestations seen in Rothmund-Thomson syndrome may be the result of photodamage, a theory supported by the site predilection for sun exposed skin, the reported abnormality of fibroblast DNA repair after UV or gamma ray exposure in affected subjects, ${ }^{14}{ }^{15}$ and the increased incidence of UV induced cutaneous malignancies. This does not explain why some of the first changes that are described occur in non-sun exposed sites.

An increased incidence of skin cancer, predominantly SCC, and bone cancer has been reported. ${ }^{79}$ There is no general increase in malignancy with osteogenic sarcoma and squamous cell carcinoma of the skin both rep- 
resenting an occasional development in tissue that is commonly dysplastic in this condition. ${ }^{24}$ While the reported skin cancers have earlier onset than in the general population, the age of onset of the reported bone malignancies is within the usual age range.

The histological abnormalities observed in case 1 parallel those reported for intrinsic cutaneous ageing (that is, skin changes associated with ageing alone, determined in non-sun exposed sites): reduced collagen content, acellularity, relative avascularity, increase of fragmented dermal elastin, with a lack of inflammation and hyperkeratosis. ${ }^{4142}$ The dermal and epidermal architecture of the skin specimen removed from the non-sun exposed site were similar to age matched controls, with rete ridge formation, cellular dermis with no inflammation, fine papillary network of collagen with thicker bundles in the reticular dermis, and with a network of elastin arcades at the dermoepidermal junction.

We propose that Rothmund-Thomson syndrome is a heterogeneous group of disorders which can manifest as photoageing changes, possibly associated with abnormal DNA repair, but also as site specific genetically programmed cutaneous ageing. Non-sun exposed skin appeared normal when compared to age matched controls (unpublished data), indicating that the premature ageing changes were confined to macroscopically affected areas. This could be secondary to mosaicism, either chromosomal, as has been reported previously for RothmundThomson syndrome associated with trisomy 8 mosaicism $^{12}$ although we have no evidence for this in our patient, or secondary to a postzygotic mutation.

This is the first report of intrinsic ageing changes in Rothmund-Thomson syndrome, and indicates that a subgroup of subjects within this syndrome could potentially serve as a model to study genetically programmed cutaneous ageing. These case reports also show that Rothmund-Thomson syndrome is even more heterogeneous than previously assumed.

The authors would like to thank Mrs A Spreadborough for expert technical assistance in the chromosomal radiosensitivity studies, the Cancer Research Campaign for continuing support of DS, Dr C Smith for referring case 2 , and case 2 herself and her family for their cooperation. GSA is supported by the Wellcome Trust.

Taylor WB. Rothmund's syndrome-Thomson's syndrome. Arch Dermatol 1957;75:236-44.

2 Rook A, Cantab MB, Whimster I. Congenital cutaneous dystrophy (Thomson's type). Br $\mathcal{F}$ Dermatol Syphilis 1949 61:197-205.

3 Bloch B, Stauffer H. Skin diseases of endocrine origin (dyshormonal dermatoses). Arch Dermatol Syphilis 1929, 19:22-34

4 Thomson MS. An hitherto undescribed familial disease. $B r$ 7 Dermatol Syphilis 1923;35:455-62.

5 Thomson MS. Poikiloderma congenitale. Br 7 Dermatol Syphilis 1936;48:220-34.

Syphilis 1936;48:220-34. ed. Baltimore: Johns Hopkins University Press, 1995.

7 Starr DG, McClure JP, Connor JM. Non-dermatological complications and genetic aspects of the Rothmundcomplications and genetic aspects of the Ro

8 Berg E, Chuang TY, Cripps D. Rothmund-Thomson syndrome. A case report, phototesting, and literature review. drome. A case report, phototesting, and

9 Vennos EM, Collins M, James WD. Rothmund-Thomson syndrome: review of the world literature. $f$ Am Acad Dermatol 1992;27:750-9.

10 Gorlin RJ, Cohen MM, Levin LS. Syndromes of the head and neck. Oxford: Oxford University Press, 1990.
11 Der Kaloustian VM, McGill JJ, Vekemans $M$, Kopelman HR. Clonal lines of aneuploid cells in Rothmund-Thomson syndrome. Am ₹ Med Genet 1990;37:336-9.

12 Ying KL, Oizumi J, Curry CJR. Rothmund-Thomson syndrome associated with trisomy 8 mosaicism. $\mathcal{F}$ Med Genet 1990;27:258-60.

13 Orstavik $\mathrm{KH}, \mathrm{McFadden} \mathrm{N}$, Hagelsteen J, et al. Instability of lymphocyte chromosomes in a girl with RothmundThomson syndrome. $\mathcal{f}$ Med Genet 1994;31:570-2.

14 Shinya A, Nishigori C, Moriwaki S, et al. A case of Rothmund-Thomson syndrome with reduced DNA repair capacity. Arch Dermatol 1993;129:332-6.

15 Smith PJ, Paterson MC. Enhanced radiosensitivity and defective DNA repair in cultured fibroblasts derived from Rothmund Thomson syndrome patients. Mutat Res 1982; Rothmund

16 Scott D, Jones LA, Elyan SAG, et al. Identification of A-T heterozygotes. In: Gatti RA, Painter RB, eds. Ataxiatelangectasia. NATO Series 1993;77:101-16.

17 Scott D, Spreadborough AR, Roberts SA. Radiation-induced $\mathrm{G}_{2}$ delay and spontaneous chromosome aberrations in ataxia-telangectasia homozygotes and heterozygotes. Int $\mathcal{7}$ Radiat Biol 1994;66:5157-63.

18 Scott D, Spreadborough A, Levine E, Roberts SA. Genetic predisposition in breast cancer. Lancet 1944;344:1444.

19 Sanford KK, Parshad R. Detection of cancer-prone individuals using cytogenetic response to X-rays. In: Obe G, Natarajan AT, eds. Chromosomal aberrations: basic and applied aspects. Berlin: Springer Verlag, 1990:113-20.

20 Parshad R, Sanford KK, Jones GM. Chromatid damage after $\mathrm{G}_{2}$-phase $\mathrm{X}$-irradiation of cells from cancer-prone individuals implicates deficiency in DNA repair. Proc Nat Acad Sci USA 1983;80:5612-16.

21 Hall JG, Pagon RA, Wilson KM. Rothmund-Thomson syndrome with severe dwarfism. Am J Dis Child 1980; 134:165-9.

22 Roth DE, Campisano LC, Callen JP, et al. RothmundThomson syndrome: a case report. Pediatr Dermatol 1989; 6:321-4.

23 Blaustein HS, Stevens AW, Stevens PD, et al. Rothmund Thomson syndrome associated with annular pancreas and duodenal stenosis:a case report. Pediatr Dermatol 1993; 10:159-63.

24 Moss C. Rothmund-Thomson syndrome: a report of two patients and a review of the literature. Brf Dermatol 1990; 122:821-9.

25 Kassner EG, Qazi QH, Haller JO. Rothmund-Thomson syndrome (poikiloderma congenitale) associated with mental retardation, growth disturbance and skeletal feamental retardation, growth disturbance

26 Cole HN, Giffen HC, Simmons JT, Stroud GM. Congenital cataracts in sisters with congenital ectodermal dysplasia. fAMA 1945;129:723-8.

27 Kauffman S, Jones M, Culler FL, Jones KL. Growth hormone deficiency in the Rothmund-Thomson syndrome. Am $\mathcal{F}$ Med Genet 1986;23:861-8.

28 Silver HK. Rothmund-Thomson syndrome:an oculocutaneous disorder. Am f Dis Child 1966;3:182-90.

29 Cohen MM, Levy HP. Chromosome instability syndromes. Adv Hum Genet 1989;18:43-9.

30 Higurashi $\mathrm{M}$, Conen PE. In vitro chromosomal radiosensitivity in chromosomal breakage syndromes. Cancer 1973;32:380-3.

31 Sanford KK, Parshad R, Price FM, et al. Enhanced chromatin damage in blood lymphocytes after $G_{2}$ phase $X-$ irradiation, a marker of the ataxia-telangestasia gene. $f$ Natl Cancer Inst 1990;82:1050-4.

32 Kuhn EM. Effects of X-irradiation in $G_{1}$ and $G_{2}$ on Bloom's syndrome and normal chromosomes. Hum Genet 1980; 54:335-41.

33 Bigelow SB, Rary JM, Bender MA. G, chromosomal radiosensitivity in Fanconi's anemia. Mutat Res 1979;63:189sen

34 Parshad R, Sanford KK, Kraemer $\mathrm{KH}$, et al. Carrier detection in xeroderma pigmentosum. $\mathcal{F}$ Clin Invest 1990 85:135-8.

35 Sanford KK, Parshad R, Gantt R, et al. Factors affecting and significance of $G_{2}$ chromatin radiosensitivity in predisposition to cancer. Int $\mathcal{F}$ Radiat Biol 1989;55:963-98.

36 Parshad R, Price FM, Pirollo EH, et al. Cytogenetic response to $G_{2}$ phase $X$-irradiation in relation to DNA repair in a cancer-prone family with Li-Fraumeni syndrome. Radiat cancer-prone family with

37 Zampetti-Bosseler F, Scott D. Cell death, chromosome damage and mitotic delay in normal human, ataxia telangectasiaia and retinoblastoma fibroblasts after $\mathrm{X}$-irradiation. Int $\mathcal{F}$ Radiat Biol 1981;39:547-58

38 Fujiwara $\mathrm{Y}$. Rothmund-Thomson syndrome. Pediatr In 1989;21:126-8.

39 Uitto J, Fazio MJ, Christiano AM. Cutis laxa and premature aging syndromes. In: Royce PM, Steinmann B, eds. Connective tissue and its heritable disorders. New York: WileyLiss, 1993:409-23.

40 Gilchrest BA. Skin aging and photoaging: an overview. $f$ Am Acad Dermatol 1989;21:610-13.

41 Ashcroft GS, Horan MA, Ferguson MWJ. The effects of aging on cutaneous wound healing in mammals. $\mathcal{F}$ Anat 1995; 187:1-29.

42 Fenske NA, Lober CW. Structural and functional changes of normal aging skin. $\mathcal{F}$ Am Acad Dermatol 1986;15:571-85. 